\title{
SINGLE NATIONAL NUMBER, A SOLUTION FOR AN OPTIMAL MANAGEMENT OF INSURANCE IN THE DEMOCRATIC REPUBLIC OF CONGO
}

\author{
Efrem Mbaki Luzayisu \\ Department of Mathematics and Computer Science, Faculty of Sciences \\ University of Kinshasa, Democratic Republic of Congo
}

\begin{abstract}
The liberalisation of the insurance market offers new economic opportunities in the Democratic Republic of Congo (DRC). Indeed, it marks the end of the monopoly of the national state company and opens the door to competition by implementing the process of transformation of an economic sector whose purpose is to allow the exercise of an economic activity to different entities, private or public. Admittedly, the approvals of the new insurers bring a lot of money into the country, but beyond everything, the legitimate questions that everyone has the right to ask is whether this transaction leads to a decrease in prices, an increase in the number of subscriptions, improved quality of service and/or expanded choice for consumers. Only, taking advantage of our expertise in Information and Communication Technologies (ICT) with a long professional experience in the development of banking software and actuaries, we try to go into depth in our questions in order to bring our little stone to the edifice. As a matter of fact, when we look at the current situation, we point out some of the dysfunctions before we make proposals to improve the system. In other words, through this document, we ask ourselves about the current information system and propose solutions for taking into account all the components of a good insurance system and for implementing the conceptual and/or technical links that unite them. Basically, we define the conditions for the implementation of an insurance information system in DR Congo that can satisfy both technical, business, political and citizen needs. This paper focuses on one of these solutions with the implementation of a single national number.
\end{abstract}

\section{KEYWORDS}

Liberalisation, Insurance, Insurer, Monitoring Authority, DRC

\section{INTRODUCTION}

We are pleased to see market liberalisation in the field of insurance in the Democratic Republic of Congo (DRC). Everyone will recall that on 23 November 1966, via Ordinance Law $N^{\circ} 66 / 0622 a$, the National Insurance Company (NIC) [la Société Nationale d'Assurances (SONAS)] came into existence with, as its primary mission, the unification of insurance activities formerly carried out by foreign private companies (Yav J.., 2021).

This development put an end to economic liberalism in this sector of economic activity in the Congo by entrusting the new company with the monopoly of all these activities. Thus, NIC became the only insurance company covering the entirety of the national insurance market (Liripa S., 2007; Wellmann A., 2004).

However, after 50 years, the Congolese government promulgated Law N¹5/005 of 17 March 2015 relating to the Insurance Code, followed by Decree No ${ }^{\circ} 16 / 001$ of 26 January 2016 relating to the creation, organisation and functioning of the Insurance Regulatory and Monitoring Authority (IRMA) [l'Autorité de Régulation et de Contrôle des Assurances (ARCA)] in order to animate this newly-liberalised market (Michael K., 2012).

This development is accompanied by a growth in competition and the arrival of new insurance products. Therefore, it represents a strong call to investors who, by their financial contributions, offer the country new employment possibilities (Ferdinand A., 2010). Furthermore, thanks to the competition, a significant decrease is hoped for in premiums for insurance contracts for all types of risk - Life or Non-Life - covered by the insurers. This document aims to analyse the insurance business-model in the RDC so as to reveal three 
points able to improve the effectiveness of good governance in this new market for insurance in the heart of Africa. With this in mind, the following is divided into four sections. Point 2, the problematic, describes our preoccupation with the insurance business-model in the RDC. Point 3 provides a succinct explanation of the current functioning of the insurance market. And point 4 describes the way in which we envisage establishing the link between IRMA and the client, so as to improve the new insurance market in the RDC by giving new powers to IRMA, thanks to underwriting data. We will finish with a brief conclusion before the bibliography.

\section{PROBLEMATIC}

Today, the insurance business-model in the RDC revolves around the Insurance Regulatory and Monitoring Authority (IRMA). This body carries out its role marvelously, wearing simultaneously three hats so as to accomplish its missions: monitoring - to identify and sanction possible abuses; advisory - to inform and steer governmental policy in insurance matters, and popularisation - to raise the awareness of the population and business regarding insurance products. From our analysis, this management model poses three problems which are presented in Figure1 below:

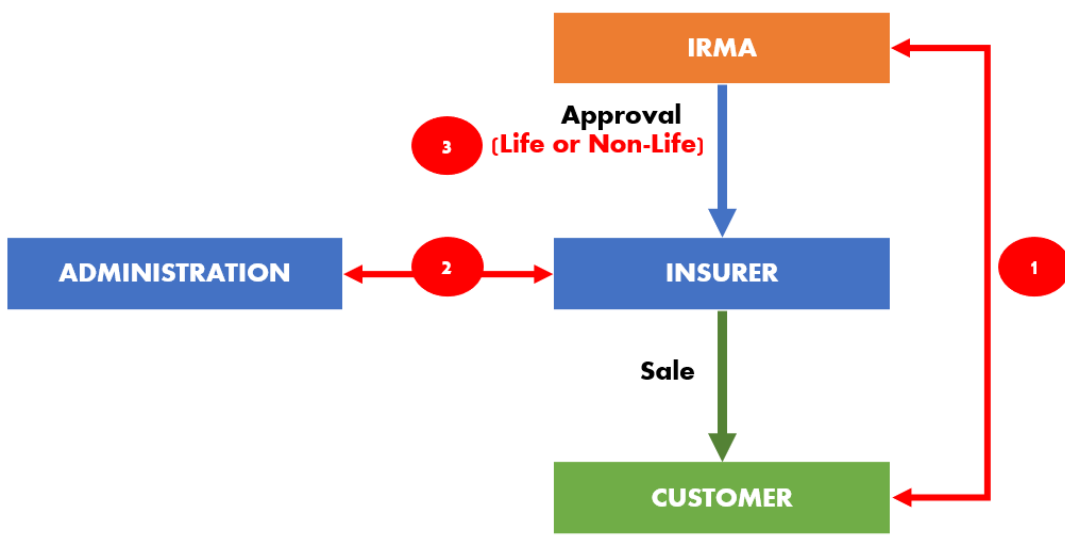

Figure 1. Business-Model and three points

Indeed, although IRMA works in harmony with business (insurers and insurance brokers), we regret that:

1. It has no contact with insurance policy-holders. In this way, it is deprived of critical information to enable it to fulfil the afore-mentioned three missions correctly ;

2. The licences are too broad : Life or Non-Life. Insurers alone define the conditions and terms for cover of one kind of risk or another. The main conern is that the insurance is in accordance with the licence obtained (Life or Non-Life) ;

3. The administrations are not closely involved in the acceptance of a request for insurance: in the majority of cases, the insurers alone study the clients' files, without prior verification with the administrations to validate or reject the declarations received.

The rest of this document attempts to shed more light on the first point concerning contact between IRMA and the policy-holder with a view to registering each client and the type of insurance being taken out. In so doing, follow-up can be organised and attempts made to propose IT solutions to overcome these shortcomings.

\section{CURRENT FUNTIONING}

To date, companies wishing to work in the new insurance market in the RDC apply to the competent authority, IRMA, for a licence. As Figure 2 below shows, by payment of the underwriter amount, which today stands at US\$10 million for one branch (Life or Non-Life), and submission of a complete file, they obtain the right to sell insurance products on the Congolese market. 


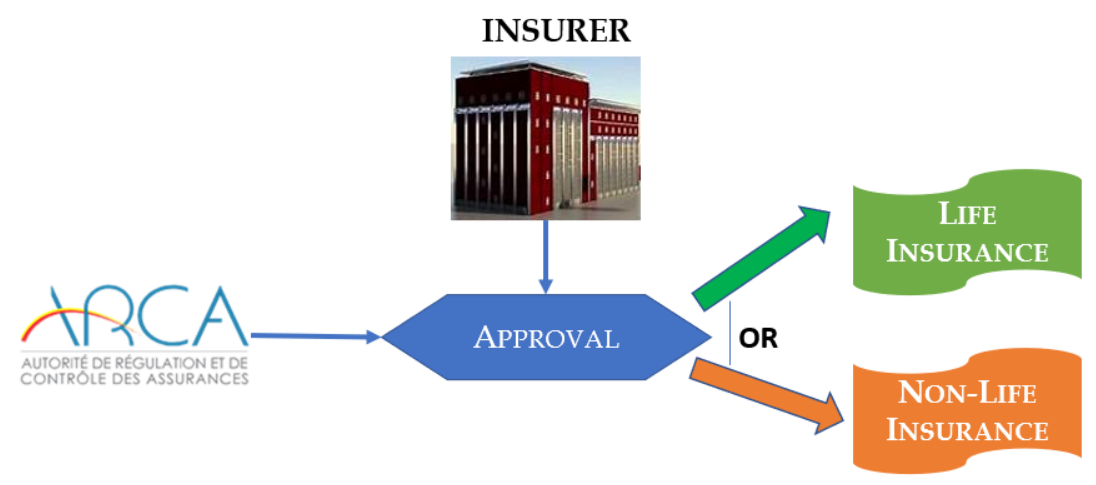

Figure 2. Underwriting an insurance company

It should be recalled that the concept of insurance implies a contractual arrangement whereby one party, the insurance company or insurer, commits to compensating loss or damages suffered by another party, the insured, by the payment of a determined amount, in exchange for an adequate consideration called a premium. As a general rule, an insurance is financial cover for an event that may occur in the future (Couilbault, and al., 2019).

Unless otherwise stated, Life insurance is a personal insurance. Payment of the premiums may be made all at once or periodically in line with the frequency determined in the contract (ARCA, 2010). Life insurance enables a person to insure for a capital sum in the event of death or life. As a general rule, life insurance concerns at least three players (Esbjörn O. and Björn J., 2014; Froment M. and Petauton P., 2017):

1. the policy-holder (the client): this is the person who takes out the life insurance with a company. This person pays the premiums for the life insurance and is the person who concludes a contract with the insurer;

2. the insured: this is the person insured. Payment will be made in the event of death or life, in accordance with the terms of the contract;

3. the beneficiary: this is the person who receives the insured capital.

On the other hand, Non-Life insurance groups together all types of insurance with the exception of Life insurance contracts. In other words, it concerns all prudential agreements which are not connected to or directly conditional upon the life of the insured person (Esbjörn O. and Björn J., 2014). In this sense, Non-Life insurance groups together those insurance operations which do not concern the life of the insured person. In all probability, Non-Life insurance groups together all conctracts of type FADR (abbreviation for Fire, Accident and Diverse Risks) [Incendie, Accidents et Risques Divers IARD)] (Suru A., 2020). It is therefore principally made up of insurance of things or belongings, insurance for responsibility or debt and insurance of persons.

In simple terms, the main difference between Non-Life insurance and Life insurance is the occurrence of the loss or damage, which is more often certain in the case of Life insurance, whereas only probable (with a probability between 0 and 1) for Non-Life insurance. Moreover, for Non-Life insurance, the cost of the loss or damage is rarely known, another specific feature (Planchet F., 2004).

Furthermore, we are not aware that IRMA imposes on insurers any list of risks to be covered. It only limits the field of activity to Life or Non-Life, according to the licence obtained. Certain companies have been able to acquire two authorisations, to sell Life and Non-Life insurance.

\section{ESTABLISH CONTACT WITH THE POLICY-HOLDERS}

As described above, under the current functioning of the insurance market in the RDC, IRMA has no contact with the policy-holders. It is therefore incapable of drawing up a table indicating for each policy-holder the kind of insurance he/she has taken out. The insurers define the conditions and operating methods for the insurance products that they market, respecting, of course, the country's laws and regulations. 
In these conditions, the insurer has sole responsibility for the monitoring and processing of the various events that may occur during the life-cycle of an insurance policy. This greatly reduces IRMA's role in its capacity to regulate the market and to intervene effectively in the event a client is mistreated.

Moreover, with this way of working, IRMA deprives itself of a significant basket of (sizeable) data able to allow it to recover its due from the insurers. Indeed, it is agreed that the insurer retrocedes to IRMA a percentage of each premium received from a client concerning an insurance policy. Without this data, it is virtually impossible for IRMA to anticipate expected revenue rationally. It is therefore dependent on the good-will of the insurers who themselves communicate the amount to be paid to the Authority.

More serious, without this data, IRMA has no control over evolution of the insurance market in order to compile statistics and draw up tables of key indicators. It cannot claim, therefore, to carry out correctly its advisory role towards the political instances who need rational information to be able to determine useful trends in the insurance market.

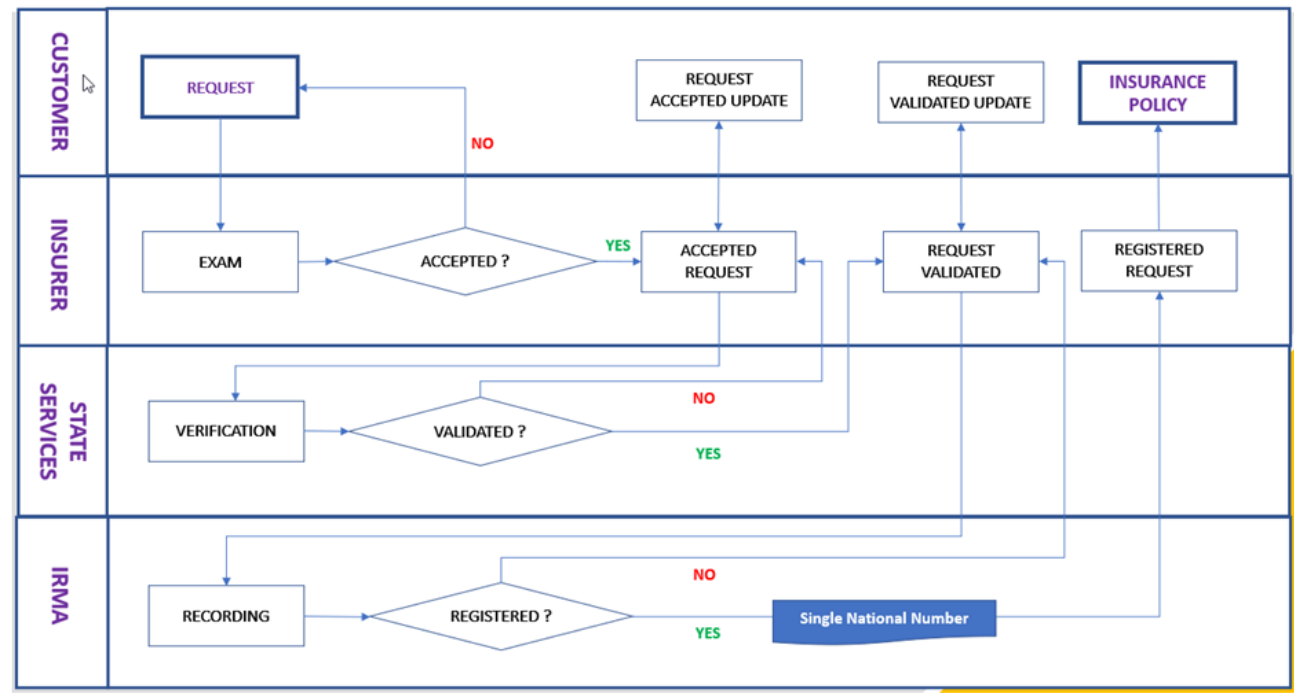

Figure 3. Flow Diagram

To overcome this inadequacy, we propose implementation of an IT system that would attribute a Single National Number (SNN) to each insurance policy. The SNN should accompany all procedures (administrative, legal and other) connected to the policy. To achieve this, the ideal solution would be to utilise an IT system able to support the flow chart shown in Figure 3 above. The client's request is in effect handled sequentially by the insurer, the administration and IRMA which validates the procedure by registering the insurance policy and providing it with an SNN. With difficulties due to the DRC context where the Internet and communication networks are problematic, we implemented and tested this system using two techniques: web services and FTP exchanges. We will take the time to explain the details of these two solutions in a separate document. In order to improve and optimise the current situation, we suggest implementation of an IT system able to support the flow-chart described above, a process resulting in the registration of every insurance policy by IRMA and the generation of a Single National Number as shown in Figure 4 above. 


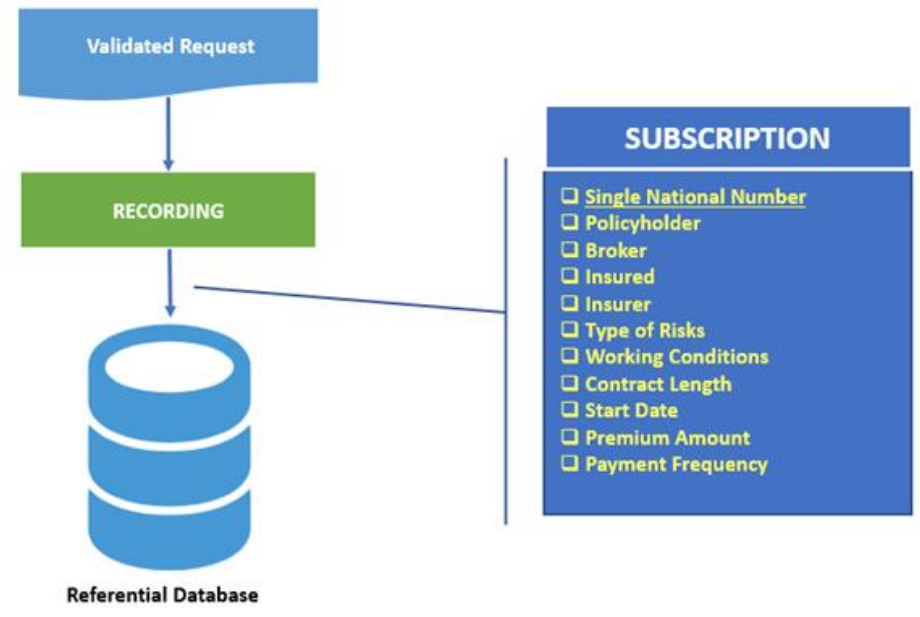

Figure 4. Registration of an insurance subscription

The subscription table that we implemented with SQL Sever is a gold mine. Indeed, its content would allow the authorities to make statistics, calculate indicators or draw up scoreboards. Similarly, actuaries would have useful data to make simulations and build models.

\section{CONCLUSION}

The foregoing clearly reveals the three shortcomings that characterise the insurance market in the RDC. Moreover, it shows the difficulties facing the competent Authority in monitoring the data which would allow it to play its role of regulator and advisor to the political instances.

Despite the concerns of the Internet and communication networks, we succeeded in implementing a solution that could allow a positive evolution of the insurance market in DR Congo. Indeed, with the registration of each insurance policy, the authorities will be able to monitor in real time the evolution of this newly reconstructed sector.

\section{REFERENCES}

ARCA, 2010. Aperçu historique des Assurances en RDC, https://arca.cd/apercu-historique-des-assurances-en-rdc/ Couilbault F. and al., 2019. Les grands principes de l'assurance, L'Argus de l'assurance, 14e édition

Esbjörn O. and Björn J., 2014. Non-Life Insurance Pricing with Generalized Linear Models, Springer; 1st ed.

Ferdinand A., 2010. Financial liberalisation and performance in the insurance industry: evidence from ghana, LAP Lambert Academic Publishing

Froment M. and Petauton P., 2017. Théorie et pratique de l'assurance-vie - 5e éd. - Cours complet et synthétique, exercices corrigés, Dunod; 5e édition

Liripa S., 2007. Rapport de stageeport of traineeship effectué à la Société Nationale d'Assurances, Université de Kisangani, Licence en Sciences économiques.

Michael K., 2012. Stochastic Models in Life Insurance, Springer; $2^{\text {nd }}$ edition

Planchet F., 2004. Assurance Non-Vie (Le modèle collectif), Support de cours 2003-2004, ISFA

Suru A., 2020. Assurance Iard, Economica

Wellmann A., 2004. Liberalisation of Trade and reduction of protectionism, GRIN Verlag $\mu$

Yav J.., 2021. Liberalization of Insurance Sector in Democratic Republic of Congo,https://www.hg.org/legalarticles/liberalization-of-insurance-sector-in-democratic-republic-of-congo-35637, consulted on 02/19/2021 